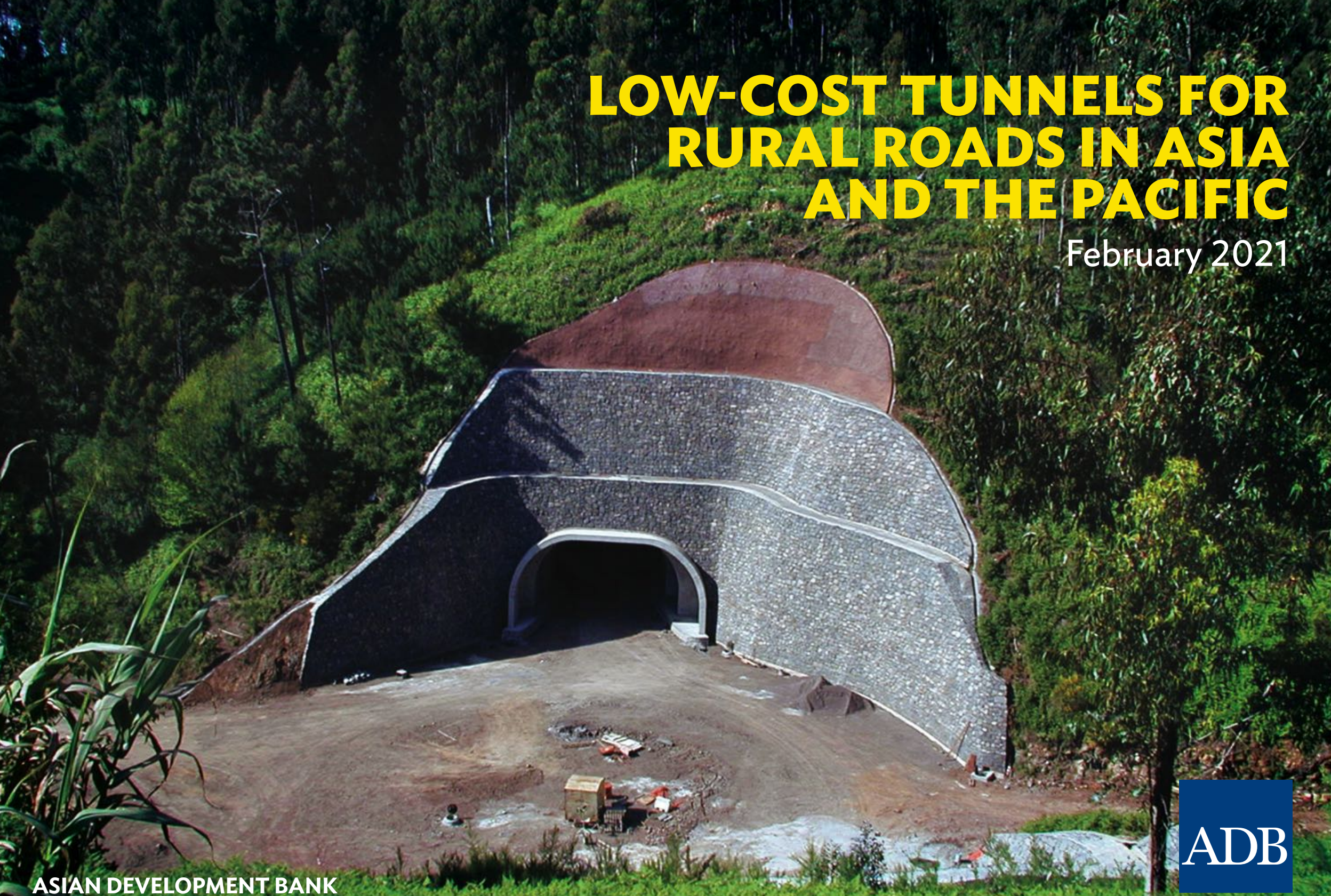

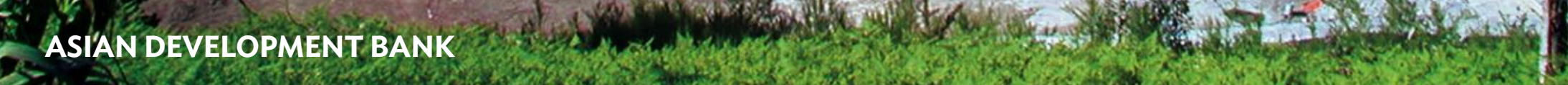

Fis 


\section{LOW-COST TUNNELS FOR RURAL ROADS IN ASIA AND THE PACIFIC}

David Salter

Principal Natural Resources and Agriculture Specialist

Environment, Natural Resources and Agriculture Division

Southeast Asia Department

Asian Development Bank

Michael Anyala

Senior Road Asset Management Specialist

Sustainable Development and Climate Change Department

Asian Development Bank

Anouj Mehta

Principal Infrastructure Specialist

Southeast Asia Department

Asian Development Bank

Jasper Cook

Roads Specialist

Director

OTB Viet Nam Ltd.

David Hindle

Tunnel Specialist

Consultant

OTB Viet Nam Ltd. 
(C) 2021 Asian Development Bank

6 ADB Avenue, Mandaluyong City, 1550 Metro Manila, Philippines

Tel +6328632 4444; Fax +63286362444

www.adb.org

All rights reserved. Published in 2021.

ISBN 978-92-9262-706-5 (print), 978-92-9262-707-2 (electronic), 978-92-9262-708-9 (ebook) Publication Stock No. ARM200212

DOI: http://dx.doi.org/10.22617/ARM200212

The views expressed in this publication are those of the authors and do not necessarily reflect the views and policies of the Asian Development Bank (ADB) or its Board of Governors or the governments they represent.

ADB does not guarantee the accuracy of the data included in this publication and accepts no responsibility for any consequence of their use. The mention of specific companies or products of manufacturers does not imply that they are endorsed or recommended by ADB

in preference to others of a similar nature that are not mentioned.

By making any designation of or reference to a particular territory or geographic area, or by using the term "country" in this document, ADB does not intend to make any judgments as to the legal or other status of any territory or area.

ADB encourages printing or copying information exclusively for personal, educational, and noncommercial use with proper acknowledgment of ADB. Users are restricted from reselling, redistributing, or creating derivative works for commercial purposes without the express, written consent of ADB. Please contact pubsmarketing@adb.org if you have questions or comments with respect to content, or if you wish to obtain copyright permission.

Corrigenda to ADB publications may be found at http://www.adb.org/publications/corrigenda.

Note:

In this publication, “\$” refers to United States dollars.

On the cover: Via Madeira highway tunnels. Local and rural road tunnels are illustrated with portal finished in local stone and colored shotcrete by artisanal labor (photo by David Hindle). 


\section{Contents}

I. Key Points 1

II. Introduction 1

III. Tunnel Impact and Sustainability 1

IV. Tunneling Methodologies 2

Excavation 2

Support 2

V. Tunneling Costs 6

VI. ADB Strategy 2030

VII. Examples of Low-Cost Rural Tunnels 9

References 10 



\section{Key Points}

Tunneling projects are often considered to have high construction cost and risk, largely because they are usually related to major infrastructure such as urban metros, high speed railways, and major highways, often in heavily populated areas where surface routes are not feasible. However, in a rural context this is not the case and tunneling can often be a cost-effective, low-maintenance alternative to a surface route through difficult terrain.
From an environmental point of view, a tunnel can greatly reduce emissions, noise and vibration, and light pollution and has a minimal impact on the local flora and fauna below which it passes, avoiding disturbance to sensitive hillside ecosystems, cultural heritage, and animal movement. It can also provide an emergency refuge for local communities, together with their livestock, against severe storms, particularly as there would be rapid and direct access via the road system.

\section{Introduction}

The corporate strategy of the Asian Development Bank (ADB) Strategy 2030: Achieving a Prosperous, Inclusive, Resilient, and Sustainable Asia and the Pacific contains the key operational priority areas of addressing remaining poverty and reducing inequalities, tackling climate change, building climate and disaster resilience, enhancing environmental sustainability, and promoting rural development and food security. Low-cost tunnels for rural roads in developing countries contribute to these ADB priorities.
The advantages of rural tunnel technology include

(i) applicability to a broad range of infrastructure including transport, sewerage, water, and power supply schemes;

(ii) savings in lengths by avoiding longer routes around or over a mountain,

(iii) reduced transport costs from improvements in gradients; and

(iv) providing an ecological "green bridge" across the highway.

\section{Tunnel Impact and Sustainability}

In a rural setting, the specifications required for major highway tunnels are far less onerous than in an urban industrialized society. The need for high levels and specifications of lighting, ventilation, and traffic control measures is greatly reduced because of the low traffic volumes. Nor does the traffic speed warrant additional lane width or alignment constraints.

The employment of local contractors, labor, and where appropriate, local materials can also contribute greatly to reducing tunneling cost. For example, if there is a local brick manufacturing industry or masonry quarry this can be used as an alternative to concrete to line the tunnel or portals; after all, most tunnels still in service after over 100 years in Europe are constructed of brick and masonry, some even dating back to Roman times.
Tunnels are incredibly durable and require a remarkably low level of maintenance; in fact the majority of tunnels ever constructed for civil engineering purposes in world history are still in use today. Operation and maintenance (O\&M) of tunnels can be financed through tolling systems that can be easily implemented. They are earthquake-resistant and relatively impervious to storms, fire, floods and other natural and human-made catastrophes.

In terms of minimizing whole-life cost, therefore, there are few, if any, other forms of infrastructure that come anywhere near the standard set by tunnels. A well-designed and well-constructed tunnel remains an important asset to the community for generations, if not centuries. 


\section{Tunneling Methodologies}

\section{Excavation}

There are numerous methods of tunnel construction available ranging from highly labor intensive hand-digging with timber support, to fully mechanized mining and tunnel boring machines. The application of a particular method depends on
(i) geology;
(ii) available manpower skill sets;
(iii) available equipment and materials; and
(iv) time, budget, and access constraints.

A tunnel in very strong rock will require less support than in weak rock but will be more difficult to excavate by hand and may require machinery and explosives. Both factors will count for and against the overall cost of the tunnel. Even in developed countries it is often more cost-effective to use labor intensive methods than to employ expensive equipment.

Larger tunnels can be hand excavated and support installed using mobile platforms or even scaffolding. Bulk muck shifting can be undertaken using basic construction equipment such as backhoes, front-end loaders, and dumper trucks.

\section{Support}

Where the tunneling ground comprises massive, strong, and intact rock, the tunnel can be safely excavated to a long-term stable profile with only minimal or no support required. In poorer ground, a temporary (primary) support is needed to stabilize the tunnel during construction and a permanent (secondary) support for long-term stability will be required. There are various cost-effective methods for supporting tunnels during construction. The most commonly used form of primary support for tunnels is a combination of sprayed concrete, also termed "shotcrete" with or without steel reinforcement and rockbolts.

There are two types of shotcrete. "Wet-mix" where the concrete is mixed in a batching plant and supplied wet, usually in a readymix truck to site. The setting of the concrete mix is chemically retarded for transportation then is accelerated using additives at the tunnel just before it is sprayed. "Dry-mix" shotcrete is supplied direct to the tunnel face in bags where it is mixed with water immediately on spraying.

(i) Wet-mix shotcreting is increasingly the preferred method in major tunneling projects because it is more easily quality controlled when supplied in bulk and is generally applied using sophisticated robotic equipment. However, for just these reasons it is less suitable for use in remote locations on smaller tunneling projects where the costs are much higher in relation to the use of dry-mix shotcreting.

(ii) Dry-mix shotcrete, on the other hand, is much more suited to smaller projects where it is not possible to provide concrete batching facilities at or near to the site. The pre-bagged shotcrete material can be supplied by trucks and mixed and pumped to the tunnel face using relatively small and inexpensive portable equipment. Application is via a hand-held nozzle where the trained operator or "nozzleman" adds water and accelerator as the material is being sprayed adjusting the water flow and additive dosage to ensure that the shotcrete sticks and sets properly.

The main disadvantages of the dry-mix method are that its successful application depends on the skill of the operator and is relatively slow compared to the bulk robotic application of wet-mix shotcrete. It also produces dust and rebound. Both can be minimized by careful application by the nozzleman, who must wear appropriate protective measures. However, its flexibility and its cost effectiveness in use make it ideal for rural tunneling projects.

Rockbolts are also a very effective means of quickly providing tunnel support and can be installed by hand using the same rock drills used to excavate the tunnel and simple hand tools. By far the most commonly 
used type of rockbolt is the resin capsule grouted steel rebar type with over a billion rockbolts consumed every year worldwide.'

Simple wood rock dowels have been used in mining to support weak rock in Australia, ${ }^{2}$ the United Kingdom, and the United States. Originally, the dowels were inserted into a close-fitting hole allowing water in the rock to wet and swell the wood to create a bond. However, this was discontinued in favor of cement grout. Similar applications of bamboo rockbolts have been used in the Asia and Pacific region and research into bamboo or steel composite rockbolts has been recently carried out. Other materials that could be considered are salvaged steel rebar, steel pipe, and wire ropes.

If the tunnel requires only minimal support then a secondary support system may not be necessary. However, if long-term tunnel stability is likely to be problematic, a secondary tunnel lining should be considered. A number of options are available, such as cast-in-situ concrete, precast concrete, and cast iron but these are generally expensive to source and install and are thereby often unsuitable for rural road tunnels.

A sprayed concrete secondary lining would be cheaper but will likely require steel reinforcement to build up the required shotcrete thickness and provide the required structural capacity. The steel reinforcement can be either standard steel weldmesh fixed to the primary lining then building up the secondary lining thickness in two or more layers fixing additional mesh to each layer as required. The more modern approach is to use steel fibers in the shotcrete mix.

A waterproofing layer can be installed between the primary and secondary support comprising either plastic sheet or sprayed-on membranes. However, this is a highly specialized and expensive process. Unless long-term water ingress is likely to be a problem, waterproofing the tunnel is not necessary, particularly if any electrical installations such as lighting and signage would be minimal or absent. Any continuous seepage can readily be piped away by fixing guttering and pipework to the tunnel roof and sidewalls.

E. Hoek. 2007. Practical Rock Engineering. https://www.rocscience.com/assets/resources/learning/hoek/ Practical-Rock-Engineering-Full-Text.pdf.

${ }^{2}$ E. Hoek and E. T. Brown. 1990. Underground Excavations in Rock. Institution of Mining and Metallurgy.
A relatively cheap, easy to install, innovative solution to the water ingress problem has recently been developed in Sweden. ${ }^{3}$ Called "rockdrain," a half-pipe polyethylene lattice is fixed to the primary shotcrete support surface using a hand-held masonry nail gun and forms drainage channels that intercept and direct water seeping through the surface to the bottom of the tunnel sidewalls where it is collected and piped away. The secondary shotcrete lining is then applied covering the rockdrain mat but still bonding to the primary support through the open lattice.

Soft ground and weak rock can often be excavated using hand tools such as by pick and shovel or using pneumatic jiggers and clay spades. In larger excavations, hydraulic breakers and mechanical backhoes can be used and adaptations are available for tunneling that assist in excavating a neat tunnel profile. However, for most hard rock tunnels, the preferred method worldwide is "drill and blast." The method, which involves the use of explosives, can be used in all types of rocks and the initial cost is lower than mechanical excavation methods.

Tunnel excavation by blasting is usually performed in the following steps:

(i) drilling blast holes,

(ii) charging the blast holes with explosives,

(iii) detonating the blast,

(iv) ventilation to blast fumes,

(v) removal of the blasted rock (mucking),

(vi) scaling crown and walls to remove loosened pieces of rock,

(vii) installing primary ground support, and

(viii) inspection surveying and logging the tunnel while advancing the tunnel services (compressed air, ventilation, lighting, etc.).

This is referred to as the tunneling cycle.

The blasting advance is normally between 1 and 3 meters depending on the ground conditions and support requirements and can usually be

\footnotetext{
3 Tunnelling Journal. 2017. Draining Away. Feb/March. pp. 32-33. https://www.tiso.no/wp-content/ uploads/2015/06/Tunnelling-Journal-February-2017.pdf.
} 
accomplished in a single 8-hour shift. Much of the work can be undertaken by unskilled or semiskilled operatives, however, a skilled lead miner who is fully trained and licensed for the use of explosives is essential. The use of explosives is inherently dangerous and there are often very strict laws in place in countries around the world on the supply, transportation, storage, and use, which will need to be addressed when planning a tunneling project.

The blast drilling pattern ensures the correct distribution of the explosive in the rock and desired blasting result. Several factors must be taken into account when designing the drilling pattern: rock drillability and blastability, the type of explosives, blast vibration restrictions and accuracy requirements of the blasted tunnel profile.

Nitroglycerine-based explosives are still commonly used and are safe provided they are handled correctly. However, there is a trend toward even safer explosive products and nonelectric methods of detonation. It is likely that strict security restrictions will be placed on the use of explosives in most, if not all, countries where this method of tunneling is employed. Normally, permits are required for the supply, transportation, storage and use of explosives and these vary from country to country. To obtain such permits, the blasting contractor's personnel directly involved in the handling and use of explosives would need to be highly trained and certified and safety considerations would need to be paramount. Most developing countries do have such expertise available, often from their indigenous mining industry.

An alternative and very sustainable form of secondary lining is stone and brick masonry. Traditionally used throughout the world, masonry lined tunnels have a remarkable proven record of long-term durability. Furthermore, quarried dressed stone and bricks are often manufactured in developing countries that have an indigenous skill base in masonry structure construction. Cut stone and brick are generally cheap to produce and easy to transport and can be used individually or in combination both to construct the tunnel lining and form the tunnel portals. The sidewalls to the tunnel are constructed exactly like a masonry retaining wall and the roof in similar manner to a bridge arch using timber formwork.
The illustration on page 5 provides a model for a basic, low-cost, and medium capacity traffic flow in a rural setting. It provides the internationally recognized standards for carriageway and verge widths and clearance heights. For lower capacity rural roads, these dimensions can be scaled down accordingly with corresponding reductions in tunnel profile and support requirements (dependent on local ground conditions).

The tunnel is a very conventional " $D$ " profile, which is simple to set out and is suitable for competent ground. Less competent ground may require curved sidewalls as well as an arched roof in a configuration commonly referred to as "horseshoe" profile. In very poor ground or high ground stress conditions, the tunnel invert profile may also need to be curved, though this is unlikely in the types of rural setting envisaged where tunnels are likely to be at relatively shallow depth.

The tunnel is provided with a shotcrete and rockbolt primary support lining and a cast-in-situ reinforced concrete base slab. A "three-course" brick lining constructed in conventional bond patterns using a timber formwork mounted on a scaffold frame (which can be mobile) to construct the arch. The brick sidewalls are founded on the reinforced concrete base slab on either side of the tunnel, which also provides a level base for erection and moving of the arch formwork. Between the brick and shotcrete lining, the gap is tightly packed with fine gravel that allows water seepage to flow down to a simple collector drain in the verge walkway on either side of the tunnel.

Where ground conditions permit one or more of these tunnel support and waterproofing elements can be reduced or omitted entirely. Furthermore, shorter tunnels, where traffic flow is minimal, could be reduced in size to single lane only controlled by traffic lights. If traffic increases with time, a second single lane tunnel alongside could be constructed at a later date. 


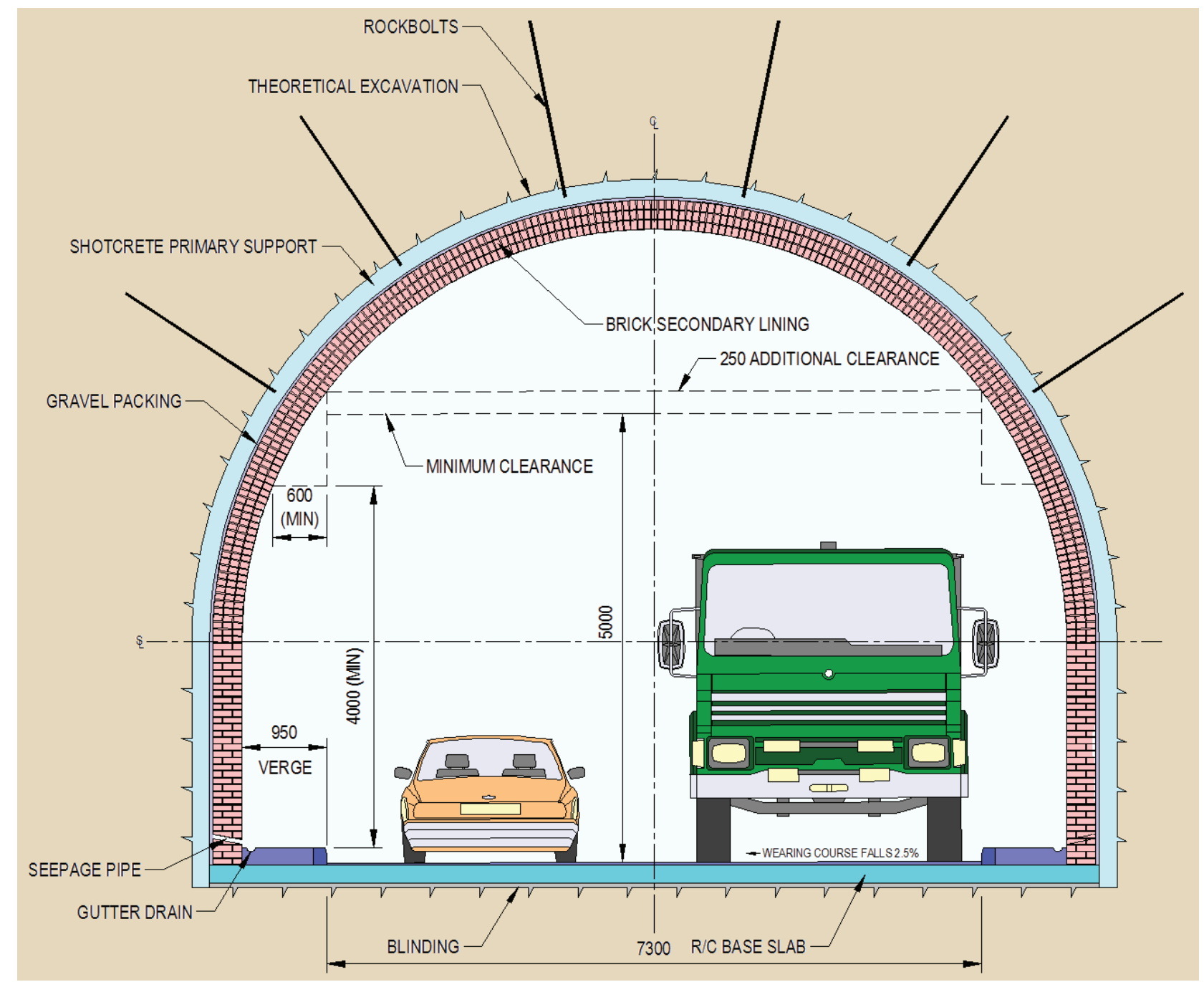

Basic highway tunnel configuration. The diagram illustrates a basic highway tunnel constructed in poor rock using a rockbolt and shotcrete primary lining and a brick arch secondary lining (source: David Hindle). 


\section{Tunneling Costs}

Tunneling costs vary widely across the world and are dependent on a number of key factors including
(i) diameter;
(ii) length;
(iii) geology;
(iv) local environment (urban, rural, etc.); and
(v) function (road, rail, water, sewerage, etc.).

For example, fully equipped two-lane highway tunnels in Europe ${ }^{4}$ and North America can cost over \$50 million per kilometer $(\mathrm{km})$ while in Norway, where they specialize in basic tunnel construction, they are less than $\$ 6$ million $/ \mathrm{km}$. A rural tunnel in a developing country could be built for a similar or even lower price as in Norway by applying appropriate design and construction methods.

When assessing a tunneling alternative to conventional road cutting construction it is important to consider the whole-life cost, in particular, long-term maintenance and environmental cost benefits. These are often overlooked when considering only the capital cost of tunnel construction. If all of the above factors are taken into account, a tunnel alternative often appears attractive and is increasingly being taken up by the developing world as a key aspect of their evolving infrastructure. The following figure illustrates the relationships between cost and outside tunnel diameter.

Tunnel Costs Related to Tunnel (outside) Diameter in Europe (2017 prices)

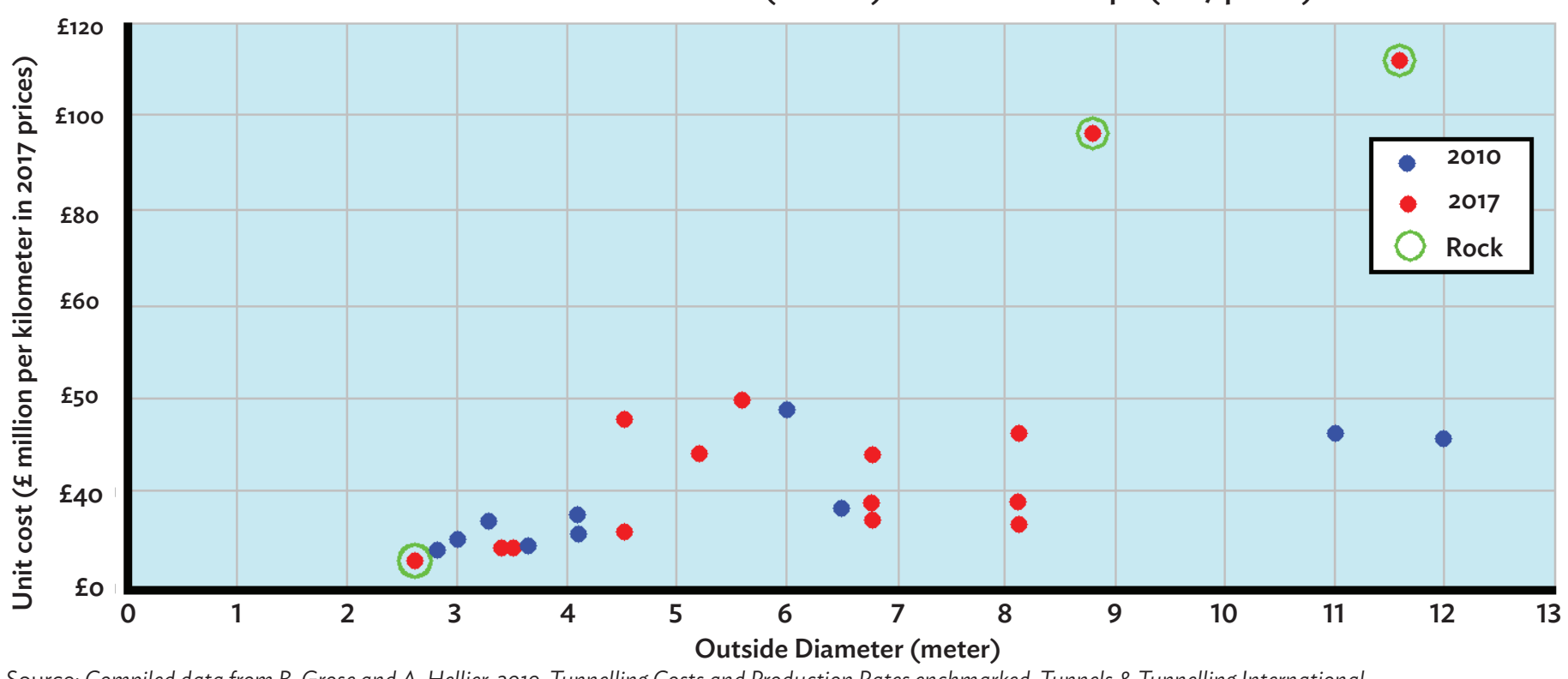

Source: Compiled data from B. Grose and A. Hellier. 2019. Tunnelling Costs and Production Rates enchmarked. Tunnels \& Tunnelling International.

${ }^{4}$ Government of the United Kingdom, HM Treasury. 2010. Infrastructure Cost Review: Technical Report. 


\section{ADB Strategy 2030}

\section{Table: Low-Cost Tunnels in Relation to ADB Strategy 2030}

\section{Operational Priorities}

Addressing Remaining Poverty and Reducing Inequalities

Accelerating Progress

in Gender Equality

Tackling Climate Change, Building Climate and Disaster Resilience, and Enhancing Environmental Sustainability

Making Cities More Livable

\section{Approach in Strategy 2030}

ADB will increase the emphasis on human development and socia inclusion to address the non-income dimensions of poverty. It will help facilitate quality job creation, including by small and mediumsized enterprises and inclusive businesses. ADB will support DMCs to improve education and training outcomes, achieve better health for all, and strengthen social protection systems and service delivery for those in need.

ADB will support targeted operations to empower women and girls, gender mainstreaming that directly narrows gender gaps, and operations with some gender elements that incorporate a few gender equality actions in the design and implementation of $A D B$ projects and programs. At least $75 \%$ of the number of ADB's committed operations (on a 3-year rolling average, including sovereign and nonsovereign operations) will promote gender equality by 2030.

ADB will scale up support in these areas. ADB will ensure that $75 \%$ of the number of its committed operations (on a 3-year rolling average, including sovereign and nonsovereign operations) will be supporting climate change mitigation and adaptation by 2030. Climate finance from ADB's own resources will reach $\$ 80$ billion cumulatively from 2019 to 2030.

ADB will provide integrated solutions to help build livable cities that are green, competitive, resilient, and inclusive. It will pursue crosscutting projects to promote urban health, urban mobility, gender equality, and environmental sustainability. ADB will help cities explore new and expand existing sources of funding, enhance inclusive and participatory urban planning, and integrate climate resilience and disaster risk management considerations into urban planning processes.

\section{Contributions of Low-Cost Tunnels}

- Tunneling enterprises and industry

- Improvement in road safety including reducing the economic and social costs of road construction

- More efficient transport

- Improve accessibility in rural mountainous areas including potentially opening up the lowest income areas

- Enable rural women to access socioeconomic opportunities

- Employment opportunities in construction, maintenance, and management

- Support achievement of ADB gender target

- Significant emissions reductions

- Protect sensitive mountain and hillside ecosystems

- Improve climate resilience

- Support achieving ADB climate change targets

- Improve rural and urban linkages for food, employment, and social services such as education 


\begin{tabular}{|c|c|c|}
\hline Operational Priorities & Approach in Strategy 2030 & Contributions of Low-Cost Tunnels \\
\hline $\begin{array}{l}\text { Promoting Rural Development } \\
\text { and Food Security }\end{array}$ & $\begin{array}{l}\text { ADB will support efforts to improve market connectivity and } \\
\text { agricultural value chain linkages. It will help DMCs increase agricultural } \\
\text { productivity and food security by boosting farm and nonfarm incomes, } \\
\text { promoting the adoption of advanced technologies and climate-smart } \\
\text { agricultural practices, and supporting the improvement of natural } \\
\text { resource management standards. It will also help DMCs enhance food } \\
\text { safety. }\end{array}$ & $\begin{array}{l}\text { - Improve rural and urban linkages for food, } \\
\text { employment, and social services such as } \\
\text { education. } \\
\text { - Reduce transport effort and costs } \\
\text { - Improve agriculture competitiveness and } \\
\text { reduce postharvest losses }\end{array}$ \\
\hline $\begin{array}{l}\text { Strengthening Governance } \\
\text { and Institutional Capacity }\end{array}$ & $\begin{array}{l}\text { ADB will support public management reforms to help DMCs improve } \\
\text { governance and createan enabling environment for sustainablegrowth. } \\
\text { It will help countries build resilience and respond to economic shocks, } \\
\text { strengthen service delivery, and improve capacity and standards. ADB } \\
\text { will uphold environmental and social safeguards, adhere to fiduciary } \\
\text { standards, and implement anti-corruption measures in all its projects } \\
\text { and programs. }\end{array}$ & $\begin{array}{l}\text { - Reduce operation and maintenance burden } \\
\text { on budgets and organizations }\end{array}$ \\
\hline $\begin{array}{l}\text { Fostering Regional Cooperation } \\
\text { and Integration }\end{array}$ & $\begin{array}{l}\text { ADB will enhance connectivity in the region and the competitiveness } \\
\text { of DMCs. It will increase support for regional public goods and } \\
\text { collective actions to mitigate cross-border risks such as climate } \\
\text { change, pollution, energy and water security, and communicable } \\
\text { and infectious diseases. ADB will also enhance financial sector } \\
\text { cooperation and strengthen subregional initiatives, including through } \\
\text { facilitating knowledge sharing and collaboration, and working with } \\
\text { emerging initiatives. }\end{array}$ & - Overall subregional connectivity improved \\
\hline
\end{tabular}

$\mathrm{ADB}=$ Asian Development Bank, $\mathrm{DMC}=$ developing member country.

Source: David Salter. 


\section{Examples of Low-Cost Rural Tunnels}
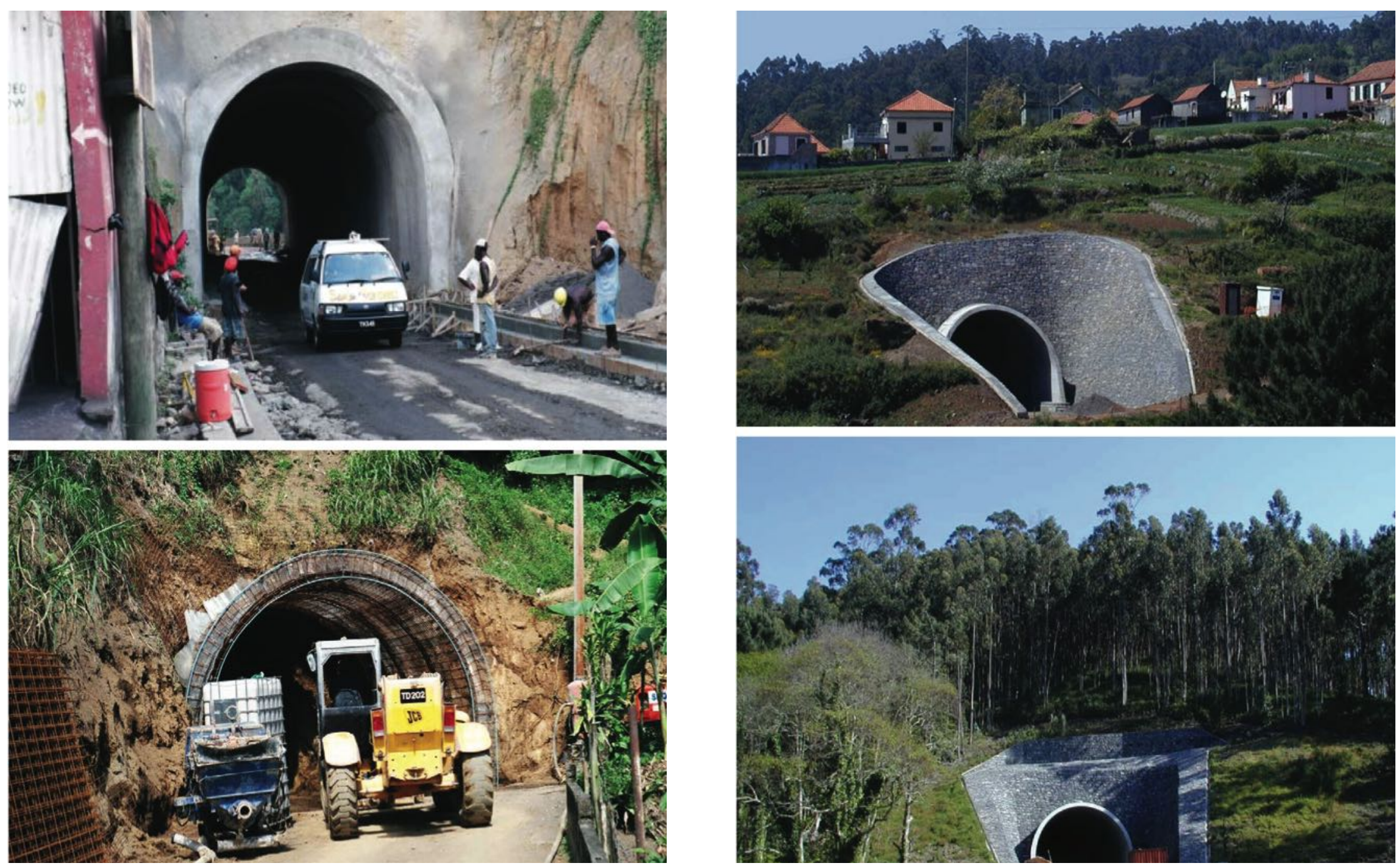

The Byera Hill (top) and Park Hill (bottom) Tunnels. These rural low-cost tunnels are located in St. Vincent (photos from Shotcrete Services Limited in the UK).

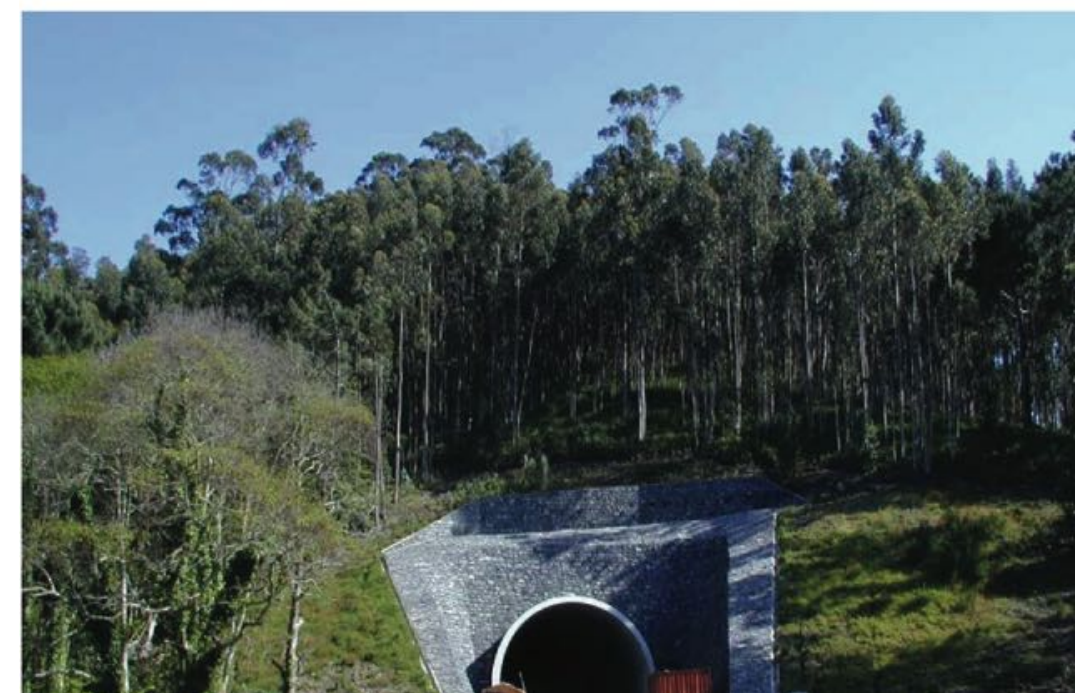

Via Madeira highway tunnels. (top and bottom) Local and rural road tunnels in Madeira with portals finished in local stone by artisanal labor (photos by David Hindle). 


\section{References}

B. Grose and A. Hellier. 2019. Tunnelling Costs and Production Rates Benchmarked. Tunnels \& Tunnelling International.

Tunnelling Journal. 2017. Draining Away. Feb/March. pp. 32-33.

E. Hoek. 2007. Practical Rock Engineering. www.rocscience.com.

E. Hoek and E. T. Brown. 1990. Underground Excavations in Rock. Institute of Mining and Metallurgy.

E. Øvstedal. 2014. Standards and Costs of Norwegian Road Tunnels. Norwegian Tunnelling Society.

Government of the United Kingdom, HM Treasury. 2010. Infrastructure Cost Review: Technical Report. December. London. 


\section{Low-Cost Tunnels for Rural Roads in Asia and the Pacific}

In rural areas, tunnels for transport, irrigation, and other purposes can provide a cost-effective, low-maintenance, and safe alternative to surface routes in difficult terrain. They also have a smaller environmental footprint by reducing emissions and lessening impacts on biodiversity and cultural heritage. Well-designed and constructed tunnels are resilient and provide rural communities with an important asset for generations, if not longer. This publication provides an overview of low-cost rural tunnels in the context of developing countries in Asia and the Pacific. It explains benefits, methodologies, and costs, and how they contribute to the Asian Development Bank's Strategy 2030.

\section{About the Asian Development Bank}

ADB is committed to achieving a prosperous, inclusive, resilient, and sustainable Asia and the Pacific, while sustaining its efforts to eradicate extreme poverty. Established in 1966, it is owned by 68 members -49 from the region. Its main instruments for helping its developing member countries are policy dialogue, loans, equity investments, guarantees, grants, and technical assistance.

\section{ADB}

